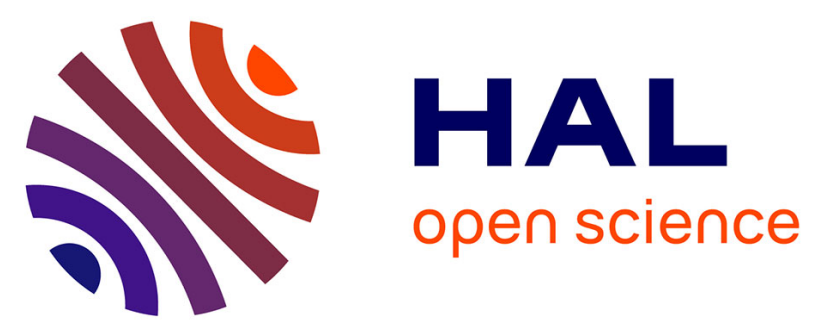

\title{
Optimization of ultrasonographic examination for the diagnosis of erosive Rheumatoid Arthritis in comparison to erosive hand Osteoarthritis
}

Camille Roux, Frédérique Gandjbakhch, Audrey Pierreisnard, Marion Couderc, Cédric Lukas, Racha Masri, Jean-Philippe Sommier, Isabelle Clerc-Urmès, Cédric Baumann, Isabelle Chary-Valckenaere, et al.

\section{To cite this version:}

Camille Roux, Frédérique Gandjbakhch, Audrey Pierreisnard, Marion Couderc, Cédric Lukas, et al.. Optimization of ultrasonographic examination for the diagnosis of erosive Rheumatoid Arthritis in comparison to erosive hand Osteoarthritis. European Journal of Radiology, 2019, 118, pp.10-18. 10.1016/j.ejrad.2019.06.003 . hal-02343399

\section{HAL Id: hal-02343399 \\ https://hal.science/hal-02343399}

Submitted on 25 Oct 2021

HAL is a multi-disciplinary open access archive for the deposit and dissemination of scientific research documents, whether they are published or not. The documents may come from teaching and research institutions in France or abroad, or from public or private research centers.
L'archive ouverte pluridisciplinaire HAL, est destinée au dépôt et à la diffusion de documents scientifiques de niveau recherche, publiés ou non, émanant des établissements d'enseignement et de recherche français ou étrangers, des laboratoires publics ou privés.

\section{(ㄷ)(1) $\$$}

Distributed under a Creative Commons Attribution - NonCommerciall 4.0 International 


\section{Optimization of ultrasonographic examination for}

\section{the diagnosis of erosive Rheumatoid Arthritis in}

\section{comparison to erosive hand Osteoarthritis}

Camille ROUX (1), Frédérique GANDJBAKHCH ${ }^{(2)}$, Audrey PIERREISNARD (2), Marion COUDERC (3), Cédric LUKAS (4), Racha MASRI (1), Jean-Philippe SOMMIER (1), Isabelle CLERC-URMES (5), Cédric BAUMANN (5), Isabelle CHARYVALCKENAERE ${ }^{(1,6)}$, Damien LOEUILLE $(1,6)$

(1) Department of Rheumatology, University Hospital of Nancy, 54500 Vandoeuvrelès-Nancy, France,

(2) Department of Rheumatology, Academic Hospital Pitie Salpêtrière, Paris,

(3) Department of Rheumatology, University Hospital of Clermont- Ferrand, ClermontFerrand,

(4) Department of Rheumatology, University Hospital of Lapeyronie, Montpellier,

(5) Platform of Clinical Research Support PARC (MDS unity), University Hospital of Nancy, 54500 Vandoeuvre-lès-Nancy, France,

(6)INSERM, CIC-EC CIE6, Nancy, France University Hospital of Nancy, Epidemiology and Clinical Evaluation, 54500 Vandoeuvre-lès-Nancy, France.

\section{CORRESPONDING AUTHOR}

Camille ROUX: Department of Rheumatology University Hospital of Nancy, 54500 Vandoeuvre-lès-Nancy, France

E-mail address: roux.cam@hotmail.fr

Phone number: +33 3831532 03; Fax number: 0383153190 
Optimization of ultrasonographic examination for the diagnosis of erosive Rheumatoid Arthritis in comparison to erosive hand Osteoarthritis 


\section{ABSTRACT}

Objective: to determine thresholds and better scenario for the diagnosis of erosive rheumatoid arthritis (RA) by ultrasonography (US) in RA in comparison to osteoarthritic (OA) patients.

Methods: Patients, prospectively included, fulfilling ACR 1987; ACR/EULAR 2010 criteria for RA or hand OA criteria. Radiographic assessment (RX): Sharp erosion score, evaluated by two blinded readers and one adjudicator for discordant cases (number of eroded joints $\leq$ three). Definition of eroded RX RA: EULAR 2013 Definition. In US, erosions were scored on six bilateral joints (MCP2-3, 5; MTP2-3, 5) with a four-grade scale.

Results: A total of 168 patients were included: 122 RA (32 early RA $<2$ years; 90 late $R A \geq 2$ years); 46 OA patients. On $R X: 42$ RA patients (6 early; 36 late) and 5 OA patients have erosive diseases (sensitivity: 34.4\%, specificity: $89.1 \%$ ). On US, 95 RA patients (21 early; 78 late) and 12 OA patients have erosive diseases. Considering at least two joint facets eroded (threshold 1) or at least one joint facet eroded at grade 2 (threshold 2), sensitivities were good (68 and 72.1\%), specificities excellent (89.1 and $100 \%$ ). With only six targeted joint facets examined (6/30), sensitivities and specificities remained good (59.8 and $60.0 \%$ ) and excellent (95.6 and 100\%) with threshold 1 and 2 respectively. For all scenarios, agreement between RX and US for erosive RA was excellent ranged from $88.1 \%$ to $92.8 \%$.

Conclusion: US erosion assessment of six targeted joint facets detected 1.7 times more erosive RA patients than $\mathrm{RX}$ in late and early RA with good sensitivity and excellent specificity.

Key Worlds: rheumatoid arthritis, osteoarthritis, ultrasounds, radiography, erosion, diagnostic score 


\section{INTRODUCTION}

Rheumatoid arthritis (RA) is the most prevalent chronic inflammatory joint disease [1,2] responsible for structural damage. To limit these consequences, an international consensus recommended a therapeutic strategy based on early diagnosis and search for poor prognostic factors in order to optimize the tight control of disease activity.[3] Erosions on radiographs (RX), high levels of biologic inflammation parameters, and the presence of anti-cyclic citrullinated peptide antibodies (ACPA) [4] are the main predictive factors of bone erosions on RX, which is considered the gold standard for visualizing and quantifying bone lesions in RA (erosions and joint space narrowing).[5] The Van der Heijde-modified Sharp score [6] with its good intra- and inter-reader reliabilities and good sensitivity to change, $[7,8]$ is considered as the standard scoring method to assess structural damage in RA. Musculoskeletal ultrasounds (US) is booming in clinical practice for the diagnosis and evaluation of inflammatory lesions from inflammatory disorders, and it has been proven to be effective in the evaluation of bone erosions in various musculoskeletal diseases: osteoarthritis $(\mathrm{OA}),[9,10]$ gout, [11] and psoriatic arthritis (PsA). [12] In RA, many studies have shown that US can detect more erosions than RX at the joint level, especially at an early stage of the disease, with higher sensitivity and specificity than $\mathrm{RX}$ when a CT scan is taken as the gold standard imaging method. [13]

It is now recognized that PsA, [14] connective tissue diseases, [15] and metabolic diseases, [16] are associated with bone erosions in hands and feet on RX, but these diagnosis, not only based on radiography, are finally established by combination of specific clinical and biological features. 
In patients aged over 50 years, the diagnosis of RA is usually established based on clinical and biological features. However, the diagnosis of erosive RA disease based on $\mathrm{RX}$ or US is sometimes difficult since bone erosions related to degenerative changes (osteoarthritis) may coexist with erosions due to RA. [1,17] Several studies have evaluated structural damages in RA, and especially erosions, in some selected joints or joint facets. $[18,19]$ We have previously shown that US examination of 12 selected Joints (30 joint facets analysed) presented a better sensitivity and specificity that radiographic EULAR 2013 Definition of erosive RA based on SHS for erosions [20] But to our knowledge, no study has evaluated the best scenario in terms of sensitivity and specificity to establish the diagnosis of erosive RA on US with a limited number of joint examined.

This study aims to determine the best scenarios to establish the diagnosis of erosive RA on ultrasonography compared to OA patients, in terms of sensitivity, specificity and agreement with erosive RA on radiography.

\section{PATIENTS AND METHODS}

\section{Population}

All consecutive patients hospitalized between $2005-2016$ for suspicion of RA in the department of Rheumatology in Nancy University Hospital were screened. Only patients fulfilling ACR 1987 and/or ACR/EULAR 2010 criteria for RA were selected for this study, patients fulfilling OA criteria served as control group. US and RX examination of hand and feet should be performed within 6 months. The only exclusion criterion was the presence of severe joint deformities that could prevent a complete appropriate clinical, US, and $\mathrm{RX}$ evaluation. A complete assessment of 
their disease was performed (clinical, biological, radiological, and ultrasound evaluations). For RA patients, data collection included the Disease Activity Score 28joint count (DAS 28) and treatments at the time of evaluation (bDMARD, SDMARD, corticosteroids, and NSAIDs). For OA patients, no treatment has been registered.

\section{Biological assessment}

The following parameters were recorded: C-reactive protein level (CRP: normal value $<5 \mathrm{mg} / \mathrm{L}$ ), erythrocyte sedimentation rate at the first hour (ESR: normal value $<5$ $\mathrm{mm}$ ), rheumatoid factor (RF) titres (normal value $<20 \mathrm{UI}$ ), and ACPA titres (normal value $<20 \mathrm{UI})$.

\section{Radiography assessment}

Postero-anterior views of hands and antero-posterior views of feet have been obtained according to the usual clinical practice recommendations for patients followed up for RA and for patients suffering from hand and/or feet OA.[21] RX analyses have been performed blindly from clinical and US information's. Two independent experimented readers (AP, MC) performed the Van der Heijde-modified Sharp score (SHS) for erosions (SHSe) with sub-scores for hands and feet. Based on this $\mathrm{RX}$ evaluation, patients were classified as erosive RA according to EULAR 2013 Definition.[22] Briefly, an erosive disease is defined when an erosion (defined as a cortical break) is observed in at least three separate joints at any of the following sites: proximal interphalangeal joints (PIP), metacarpophalangeal joints (MCP), wrist (counted as one joint), and metatarsophalangeal joints (MTP) on radiographs of both 
hands and feet. In the case of discordance between the two readers for a number of eroded joints less than or equal to three (corresponding to the threshold for erosive RA), a third reader (ICV) served as blinded adjudicator. For each patient, the SHSe corresponded to the mean score of the two or three readers.

\section{Ultrasound assessment}

Standardized US examinations were performed by senior US analysts (ICV, DL, JPS) after several sessions of harmonization for calibration of erosion. The equipment used throughout the study was the same: a Philips HD11 machine with a multi-frequency linear array transducer $(5-12 \mathrm{MHz})$ with the focal length adjusted to the joint depth. US data were acquired at optimal technical conditions at $12 \mathrm{MHz}$ (spatial resolution $0.1 \mathrm{~mm}$ ) blinded to clinical, biologic, and radiologic findings.

Twelve pre-selected targeted joints have been systematically examined on B mode:

metacarpophalangeal joints (MCPs) 2, 3, and 5 and metarsophalangeal joints (MTPs) 2, 3, and 5. MCP4 and MTP4 joints, less commonly affected by erosions in RA $[13,23,24]$; MCP1 and MTP1 joints, more frequently damaged by degenerative changes or metabolic diseases, were not included.

\section{Localization and grading of erosions}

Erosions were searched on the dorsal (D), palmar/plantar (P) facets of each joint and on the lateral (L) facets when accessible (MCP2, MCP5 and MTP5). On each facet, erosion was defined as a cortical defect with an irregular bone surface, observed in two perpendicular planes (axial and longitudinal). Erosions were scored semi- 
quantitatively according to 4 grades: grade $0=$ no erosion; grade $1=$ single erosion $<2 \mathrm{~mm}$ in its largest dimension; grade 2 = single erosion $\geq 2 \mathrm{~mm}$ and $<3 \mathrm{~mm}$ in its largest dimension or no more than two erosions $<2 \mathrm{~mm}$; and grade $3=$ single erosion $\geq$ to $3 \mathrm{~mm}$ in its largest dimension or multiple erosions $(n \geq 2)$. The total US score for erosions (USSe) was the sum of erosion grades for all eroded joints and ranged from 0 to 90 .

\section{Statistical analysis}

Characteristics of patients were described by number and percentage for categorical variables and by mean and standard deviation for continuous variables. For comparison, parametric statistics (Chi-square test, McNemar test, and ANOVA Fstatistic) or non-parametric statistics (Fisher exact, Wilcoxon tests) were used when appropriate. The diagnostic performances (sensitivity, specificity, positive predictive value (PPV), and negative predictive value (NPV)) have been analysed. Sensitivity analyses of the threshold for dichotomizing the diagnosis of erosive RA based on RX and US were performed. Alpha risk was $5 \%$ for all analyses. These statistical analyses were performed using SAS 9.4 software (SAS Institute, Inc, Cary, N.C.).

The ethical committee of Nancy approved in June 2017 this study (Number of recording: R2017-17). The consents of the patients were given orally. 


\section{RESULTS}

\section{Demographic characteristics of the population}

During the study period, 168 patients were included. Among them, 122 patients (72.6\%) belonged to the RA group and were separated into early RA (disease duration of less than 2 years, $n=32$ ) and late RA (disease duration of 2 years or more, $n=90)$, and 46 patients $(27,4 \%)$ belonged to the OA group. Gender and age (mean age: $54.9 \pm 13.5$ years for RA patients and $56.8 \pm 9.6$ for OA patients) did not differ between groups $(p=0.4204$ and $p=0.3781$ respectively). The demographic characteristics are detailed in table 1.

\section{Radiographic evaluation}

\section{Reproducibility for SHSe}

Among the 168 exams, 99 (58.9\%) matched between the two readers for a number of eroded joints less than or equal to three. A third reading was necessary for 69 patients $(41.1 \%)$ who were statistically younger $(53.1 \pm 11.2$ vs $58.8 \pm 13.6 ; p=0.0035)$.

\section{Characteristics of $R X$ erosions}

\section{Prevalence, localization and severity of RX erosions}

For the 168 patients $12 \mathrm{OA}$ and $72 \mathrm{RA}$ patients (12 early RA and 60 late RA) presented at least one erosion. Details of eroded joints in the two populations were presented in table 2. On radiography, 29 eroded joints (1.0\%) in the OA group and 
$272(9.5 \%)$ in the RA group were identified $(p<.0001)$. The mean SHSe was significantly different between OA and RA groups, and also between total population, early and late RA groups respectively $(p<.0001)$ ((table 2$)$.

\section{Discriminant joints between RA and OA}

Compared to OA: MCP1, MCP2, MCP3, MTP3, MTP4 and MTP5 joints were significantly more frequently eroded in RA groups, and only MTP3 and MTP5 joints in early RA (see results in table 2). Erosions of the MTP2 joints were more frequently observed in OA patients.

Number of patients (OA and RA) responding to the definition of erosive RA regarding to EULAR 2013 Definition

In OA group, 12 patients (26.1\%) presented at least one erosion, for whom 5 (10.8\%) satisfied with EULAR 2013 Definition of erosive disease (table 2). In the RA group, 72 patients (59.0\%) presented at least one erosion for whom $42(71.2 \%)$ satisfied with EULAR 2013 Definition of erosive disease (six (4.9\%) in early RA and 36 $(29.5 \%)$ in late RA). The sensitivity and specificity were calculated at $34.4 \%$ and $89.1 \%$, respectively.

\section{Ultrasound evaluation}

\section{Intra- and inter-examiner US reproducibility}

Intra-examiner reproducibility was assessed on 11 RA patients according to two complete examinations per patient within 24 hours. Inter-examiner reproducibility was 
assessed on 11 RA patients examined independently on the same day by each US operator. For intra-examiner reproducibility, the median value of the total US erosion score was 21 (range: 3-35) for the first exercise and 21 (range: 3-34) for the second. The intra-class correlation coefficient (ICC) values of the erosion US score for intraand inter-examiner studies were 0.96 (CI95: 0.93-0.98) and 0.97 (Cl95: 0.92-0.99), respectively. The inter reader reliability for the diagnosis of erosion was excellent (Gwet's AC1: 0.80)

\section{Characteristics of erosions}

\section{Prevalence, localization and severity of US erosions}

For the 168 patients, 12 (26.1\%) patients and 95 (77.9\%) patients (21 $(22.1 \%)$ early RA and 74 (77.9\%) late RA) were eroded in OA and RA groups, respectively. Details of eroded joints in the two populations were presented in table 3. Twelve OA patients (26.1\%) presented one erosion, and five patients had an erosion of grade 2. In RA patients, the distribution of erosions prevailed on lateral facets, independently of disease duration. MTP5 joints were the most frequently eroded joints $(46.5 \%)$, followed by MCP2 (27.3\%) and MCP5 joints (14.7\%); details are presented in figures 1,2 and 3 and table 3.

The mean USSe was significantly different between OA and RA groups but also for total population, early and late RA groups respectively $(p<.0001)$ (table 3$)$

\section{Discriminant joints between RA and OA}

Only MTP2 joint was not discriminant between RA and OA patients. (See table 3). In early RA, the three following joints: MCP2, MCP5 and MTP5 joints, were discriminant to establish a diagnosis of erosive RA on US (see table 3). As well, the 
lateral joint facets alone were also discriminant for these three joints with the palmar joint facets of MCP2 joints and plantar joint facets of the MTP5 joints (see table 3).

\section{Definition of erosive RA on ultrasound}

The presence of at least two eroded joint facets presented the better compromise in terms of sensitivity and specificity $(68.0 \%$ and $100.0 \%$, respectively) (table 4$)$. Considering the severity of the erosion at the joint facet level, whatever its localization, the presence of at least one erosion of grade 2 presented the best sensitivity (72.1\%) and specificity (89.1\%) ratios (table 4)

Eighty-three RA (68.0\%) (14 (16.9\%) early RA and 69 (83.1\%) late RA) and zero OA patients satisfied with definition of erosive RA with at least two US eroded joint facets. Considering the presence of at least one US erosion of grade 2 at joint facet level, 81 RA patients (66.4\%) (11 (13.6\%) early RA and 70 (86.4\%) late RA) and five (10.9\%) OA patients were classified with erosive disease (table 4). In order to optimize the US examination (number of joint assessed, time of duration for US examination), different scenarios are presented in table 4 . These scenarios took into account the prevalence and the severity of erosion for each joint facet assessed in RA group in comparison to OA group. Whatever the scenario chosen, the specificity remained excellent (> 90\%) with a sensitivity still preserved (> 59.8\%). For the shorter scenario with only six targeted joint facets examined (MCP2L + MTP5P + MTP5L) 73 of 83 RA patients (87.9\%) according to at least two eroded joint facets, and 74 of 81 RA patients (91.3\%) according to at least one erosion of grade 2 at joint facet level, were still classified with erosive disease on US. 


\section{Diagnostic values of US compared to $\mathrm{RX}$ and agreements between RX and US for the diagnosis of erosive RA.}

According to radiographic assessment, $42 \mathrm{RA}$ (six early RA and 36 late RA) and five OA patients satisfied with EULAR 2013 Definition for erosive RA. The agreements between RX and US, with all joints facets examined ( $N=30)$, according to the two US thresholds (at least two eroded joint facets or at least one erosion of grade 2) were $90.4 \%$ and $92.8 \%$ respectively.

With only six targeted joint facets examined (MCP2L + MTP5P + MTP5L), the agreements between US and RX for the two US thresholds (at least two eroded joint facets or at least one erosion of grade 2), were $88.1 \%$ and $92.8 \%$ respectively (table 4). These scenarios permitted to identify from 1.7 to 2 times more eroded patients with US in comparison to radiography $(p<0.0001)$. In early RA group, 12 and 10 patients were identified with erosive disease for at least two eroded joint facets and for at least one erosion of grade 2 at joint facet level, respectively, with an agreement between both imaging techniques of $88.6 \%$ and $92.8 \%$, respectively (table 4 ). In figure 5 was presented an example of early RA patient without EULAR definition of eroded RA with no erosion on radiography and at least three erosions (one erosion of grade 1 and two erosions of grade 2 and 3) detected at ultrasound examination. For patients with positive RX and negative US for erosion, radiographic assessment showed erosions on region explored on US $(n=10)$ and on region not explored on US: wrists $(n=6), \operatorname{MCP} 1(n=2), \operatorname{MCP} 4$ joint $(n=1)$ and MTP4 joint $(n=1)$. 


\section{DISCUSSION}

The aim of this study was to determine the most informative joints by US assessment to establish the diagnosis of erosive disease in RA, compared to OA patients in order to propose the best scenario for the diagnosis of erosive RA and to optimize US examination, according to two different approaches: 1) a minimal number of eroded joint facets $(n=2) 2$ ) a minimal grade of severity for at least one joint facet eroded (grade 2).

Until now, ultrasonography in RA demonstrated its performance in terms of diagnosis of inflammatory lesions (synovitis, tenosynovitis) and its sensitivity to change to the treatment.[25-28] This technique also offers many advantages (accessibility, cost, and lack of irradiation) with good intra- and inter-reliabilities for assessing structural damage and especially erosion in RA and in other musculoskeletal diseases (PsA, hand OA). [9,11,29] Our results confirmed excellent intra- and inter-ultrasonographer reliability with respect to grading erosions in patients examined in real life conditions. $[18,19,30-32]$ In this study, US joint examination was limited at some selected joints because not all the joints evaluated using the SHS can be explored in clinical practice. We decided, as other authors have done, to exclude the wrist because of its anatomic characteristics that make it difficult to localize erosions with precision in axial and longitudinal planes, except for the ulnar styloid process, where detection of these erosion seems easier.[30] We also excluded: MCP1, MTP1 and all PIP joints because these joints may be eroded by other musculoskeletal diseases and especially by osteoarthritis (the most prevalent disease in patients over 50 years old). $[19,23,33]$ We excluded patients with severe joint deformities because this exam 
performs poorly in this situation and is inappropriate (joints not well visualized and erosion not clearly identified on two perpendicular planes).[34]

In late and early RA, we confirmed on US that, the MTP5 joints, the MCP2 joints, and then the MCP5 joints are the most prevalent eroded joints detected by ultrasound, especially in the lateral and plantar/palmar joint facets. When the severity of erosion was assessed by US, the MTP5 and MCP2 joints presented the most severe lesions, as shown by other studies.[30,34,35] . In OA patients, MCP2 followed by MTP5 joints was also the most frequently eroded joints with a prevalence varying from 5 to $13 \%$ according to the joint examined, but none of these joints was severely eroded.[30] In our study, five OA patients presented erosion of grade $2(10.3 \%)$, whereas Zayat et al [30] did not find severe erosion in OA patients. With a threshold of two eroded joint facets, whatever the grade of severity observed, we calculated a sensitivity of $68.0 \%$ with a specificity of $100.0 \%$. According to the most prevalent and the most severe joint facets eroded, we scheduled five scenarios, varying between 30 joint facets and six joint facets assessed. Whatever the scenario chosen, the specificity remained excellent (> 90\%) with a sensitivity superior to $59.8 \%$. With only six joint facets examined, less than $15 \%$ of patients with erosive RA disease, diagnosed on all joint facets assessed were not identified as erosive RA disease. The agreement between RX (three joints eroded) and US was still excellent over $88.1 \%$. In the literature, four scores of US erosions were compared to radiographic assessment: two according to the SHS, $[18,28]$ one with Steinbrocker score [36] and one with a short version of the SHS with a selection of seven joints. [37] In these studies, where radiographic evaluation were performed by one or two readers the authors confirmed the superiority of ultrasound to detect erosions but they were unable to define a threshold from which an erosive RA disease on US can be established due to the 
lack of a control group.

On radiography, the diagnosis of erosive $\mathrm{RA}$ in hands and feet is routinely performed in clinical practice. Moreover, RX serves as the gold standard for diagnosis of erosive disease if at least three selected joints are eroded.[22] The diagnosis of eroded disease in RA is crucial since structural damages are associated with poor functional outcome and considered as poor prognostic factors leading to a more aggressive therapy. RX presents many advantages: the views and the technical parameters are well defined and the diagnosis of erosive RA is easily established after a careful reading performed for few seconds. The modified SHS is considered one of the standard methods for assessing structural effects of RA DMARDs (synthetic or biologic) in clinical trials because it presents excellent intra- or inter-reader reliabilities and a good sensitivity to change.[8,38] To limit reading biases, two senior readers of the ESPOIR's cohort [18] blindly assessed the Sharp-erosion score, and an adjudication was made by a third senior reader, permitting us to retain the diagnosis of 42 RA patients with erosive disease and of five patients with erosive OA. On the 44 joints assessed, MTP5 and wrists joints were most frequently eroded as described in the literature in RA.[39] Finally, the EULAR task force retained the diagnosis of erosive RA on radiography by the presence of at least three eroded joints in two cohorts of early arthritis with sensitivities and specificities calculated at $15-29 \%$ and at $>80 \%$ respectively.[18,40] With patients with hand OA considered as control, we calculated a sensitivity and a specificity at $34.4 \%$ and $89.1 \%$, respectively.

In 2000, Wakefield et al [13] demonstrated that ultrasonography permits to detect, at the joint level, 6.5 times more erosions in early RA disease and 3.5 times more erosions in late RA, than radiography. The superiority of ultrasound was confirmed in 
other studies [24,41] but also when CT scans served as the gold standard.[42] Our study demonstrated, on 30 joint facets examined, that ultrasound detected 2.0 times more eroded RA patients than radiography with a threshold of at least two eroded joint facets and 1.9 times more patients than radiography according to Sharp's score approach, with a threshold of at least one erosion of grade 2 at joint facet level with excellent specificities $(100.0 \%$ and $89.1 \%$, respectively). With the scenario of six targeted joint facets examined (MCP2L + MTP5P + MTP5L), the ratio remained stable with 1.7 times more patients with erosive disease on US than RX and may reduce the time of the US examination from 20 to 10 minutes. When early RA were examined, ultrasonography is able to detect two times more erosive RA than radiography. This discrepancy is explained by the presence of erosions on wrist on radiography, joint difficult to be examined on US due its anatomic structure. In this situation, both RX and US seems to be complementary and should be performed in order to optimize the diagnosis of erosive RA.

This pilot study performed by trained sonographers required the development of an external validation process such as the OMERACT filter. The sensitivity to change should also be tested, and the relationship between bone erosion and joint inflammation at the joint level and in the different scenarios should be also investigated. Of course, radiographic and ultrasonographic patterns of erosion in other musculoskeletal diseases were not evaluated in this study and could be evaluated in the future. Finally, joint space assessment, not performed in this study and recently validated by Mandl et al, [43] should also be investigated to improve the structural approach by US . 
To conclude, we demonstrated that bone erosions assessed by US were reliable and may be observed in both diseases, with a higher prevalence and severity in RA. US erosion assessment of only six targeted joint facets (MCP2L + MTP5P + MTP5L) permit to detect 1.7 times more patients with erosive $\mathrm{RA}$ than $\mathrm{RX}$ with a good sensitivity (>59.8\%), an excellent specificity $(>95.6 \%)$ and an excellent agreement between both imaging techniques (>88.1\%). More in early RA than in established RA, US examination and radiography should be performed together in order to optimize the diagnosis of erosive disease.

This research did not receive any specific grant from funding agencies in the public, commercial, or not-for-profit sectors. 


\section{REFERENCES}

[1]. Guillemin F, Saraux A, Guggenbuhl P, Roux CH, Fardellone P, Le Bihan E, et al. Prevalence of rheumatoid arthritis in France: 2001. Ann Rheum Dis. 2005 Oct;64(10):142730.

[2]. Alamanos Y, Voulgari PV, Drosos AA. Incidence and prevalence of rheumatoid arthritis, based on the 1987 American College of Rheumatology criteria: a systematic review. Semin Arthritis Rheum. 2006 Dec;36(3):182-8.

[3]. van Aken J, Lard LR, le Cessie S, Hazes JMW, Breedveld FC, Huizinga TWJ. Radiological outcome after four years of early versus delayed treatment strategy in patients with recent onset rheumatoid arthritis. Ann Rheum Dis. 2004 Mar;63(3):274-9.

[4]. Aletaha D, Neogi T, Silman AJ, Funovits J, Felson DT, Bingham CO, et al. 2010 rheumatoid arthritis classification criteria: an American College of Rheumatology/European League Against Rheumatism collaborative initiative. Ann Rheum Dis. 2010 Sep;69(9):1580-8. [5]. Baillet A, Gaujoux-Viala C, Mouterde G, Pham T, Tebib J, Saraux A, et al. Comparison of the efficacy of sonography, magnetic resonance imaging and conventional radiography for the detection of bone erosions in rheumatoid arthritis patients: a systematic review and meta-analysis. Rheumatol Oxf Engl. 2011 Jun;50(6):1137-47.

[6]. van der Heijde DM, van Leeuwen MA, van Riel PL, van de Putte LB. Radiographic progression on radiographs of hands and feet during the first 3 years of rheumatoid arthritis measured according to Sharp's method (van der Heijde modification). J Rheumatol. 1995 Sep;22(9):1792-6.

[7]. van der Heijde D. How to read radiographs according to the Sharp/van der Heijde method. J Rheumatol. 2000 Jan;27(1):261-3.

[8]. van der Heijde D, Dankert T, Nieman F, Rau R, Boers M. Reliability and sensitivity to change of a simplification of the Sharp/van der Heijde radiological assessment in rheumatoid arthritis. Rheumatol Oxf Engl. 1999 Oct;38(10):941-7.

[9]. Usón J, Fernández-Espartero C, Villaverde V, Condés E, Godo J, Martínez-Blasco MJ, et al. Symptomatic and asymptomatic interphalageal osteoarthritis: An ultrasonographic study. Reumatol Clin. 2014 Oct;10(5):278-82.

[10]. Vlychou M, Koutroumpas A, Alexiou I, Fezoulidis I, Sakkas LI. High-resolution ultrasonography and 3.0 T magnetic resonance imaging in erosive and nodal hand osteoarthritis: high frequency of erosions in nodal osteoarthritis. Clin Rheumatol. 2013 Jun;32(6):755-62.

[11]. Gutierrez M, Schmidt WA, Thiele RG, Keen HI, Kaeley GS, Naredo E, et al. International Consensus for ultrasound lesions in gout: results of Delphi process and webreliability exercise. Rheumatol Oxf Engl. 2015 Oct;54(10):1797-805.

[12]. Weiner SM, Jurenz S, Uhl M, Lange-Nolde A, Warnatz K, Peter HH, et al. Ultrasonography in the assessment of peripheral joint involvement in psoriatic arthritis : a comparison with radiography, MRI and scintigraphy. Clin Rheumatol. 2008 Aug;27(8):983-9. [13]. Wakefield RJ, Gibbon WW, Conaghan PG, O'Connor P, McGonagle D, Pease C, et al. The value of sonography in the detection of bone erosions in patients with rheumatoid arthritis: A comparison with conventional radiography. Arthritis Rheum. 2000 Dec 1;43(12):2762-70. 
[14]. Jadon DR, Shaddick G, Tillett W, Korendowych E, Robinson G, Waldron N, et al. Psoriatic Arthritis Mutilans: Characteristics and Natural Radiographic History. J Rheumatol. 2015 Jul;42(7):1169-76.

[15]. Alarcón-Segovia D, Abud-Mendoza C, Diaz-Jouanen E, Iglesias A, De los Reyes V, Hernández-Ortiz J. Deforming arthropathy of the hands in systemic lupus erythematosus. J Rheumatol. 1988 Jan;15(1):65-9.

[16]. Dalbeth N, Clark B, McQueen F, Doyle A, Taylor W. Validation of a radiographic damage index in chronic gout. Arthritis Rheum. 2007 Aug 15;57(6):1067-73.

[17]. Haugen IK, Englund M, Aliabadi P, Niu J, Clancy M, Kvien TK, et al. Prevalence, incidence and progression of hand osteoarthritis in the general population: the Framingham Osteoarthritis Study. Ann Rheum Dis. 2011 Sep;70(9):1581-6.

[18]. Funck-Brentano T, Etchepare F, Joulin SJ, Gandjbakch F, Pensec VD, Cyteval C, et al. Benefits of ultrasonography in the management of early arthritis: a cross-sectional study of baseline data from the ESPOIR cohort. Rheumatol Oxf Engl. 2009 Dec;48(12):1515-9.

[19]. Wakefield RJ, Gibbon WW, Conaghan PG, O'Connor P, McGonagle D, Pease C, et al. The value of sonography in the detection of bone erosions in patients with rheumatoid arthritis: a comparison with conventional radiography. Arthritis Rheum. 2000 Dec;43(12):2762-70.

[20]. Roux C, Gandjbakhch F, Pierreisnard A, Couderc M, Lukas C, Masri R, et al. Ultrasonographic criteria for the diagnosis of erosive rheumatoid arthritis using osteoarthritic patients as controls compared to validated radiographic criteria. Joint Bone Spine [Internet]. 2019 Jan 31 [cited 2019 Feb 2]; Available from: http://www.sciencedirect.com/science/article/pii/S1297319X18301647 [21]. Altman R, Alarcón G, Appelrouth D, Bloch D, Borenstein D, Brandt K, et al. The American College of Rheumatology criteria for the classification and reporting of osteoarthritis of the hand. Arthritis Rheum. 1990 Nov;33(11):1601-10.

[22]. van der Heijde D, van der Helm-van Mil AHM, Aletaha D, Bingham CO, Burmester GR, Dougados $M$, et al. EULAR definition of erosive disease in light of the 2010 ACR/EULAR rheumatoid arthritis classification criteria. Ann Rheum Dis. 2013 Apr;72(4):479-81. [23]. Scheel AK, Hermann K-GA, Ohrndorf S, Werner C, Schirmer C, Detert J, et al. Prospective 7 year follow up imaging study comparing radiography, ultrasonography, and magnetic resonance imaging in rheumatoid arthritis finger joints. Ann Rheum Dis. 2006 May;65(5):595-600.

[24]. Szkudlarek M, Klarlund M, Narvestad E, Court-Payen M, Strandberg C, Jensen KE, et al. Ultrasonography of the metacarpophalangeal and proximal interphalangeal joints in rheumatoid arthritis: a comparison with magnetic resonance imaging, conventional radiography and clinical examination. Arthritis Res Ther. 2006;8(2):R52.

[25]. Szkudlarek M, Court-Payen M, Jacobsen S, Klarlund M, Thomsen HS, Østergaard M. Interobserver agreement in ultrasonography of the finger and toe joints in rheumatoid arthritis. Arthritis Rheum. 2003 Apr;48(4):955-62.

[26]. Szkudlarek M, Narvestad E, Klarlund M, Court-Payen M, Thomsen HS, Østergaard M. Ultrasonography of the metatarsophalangeal joints in rheumatoid arthritis: comparison with magnetic resonance imaging, conventional radiography, and clinical examination. Arthritis Rheum. 2004 Jul;50(7):2103-12.

[27]. Backhaus M, Ohrndorf S, Kellner H, Strunk J, Backhaus TM, Hartung W, et al. Evaluation of a novel 7-joint ultrasound score in daily rheumatologic practice: A pilot project. Arthritis Care Res. 2009 Sep 15;61(9):1194-201. 
[28]. Luz KR, Pinheiro MM, Petterle GS, Dos Santos MF, Fernandes ARC, Natour J, et al. A new musculoskeletal ultrasound scoring system (US10) of the hands and wrist joints for evaluation of early rheumatoid arthritis patients. Rev Bras Reumatol. $2016 \mathrm{Jul}$ 8;

[29]. Wiell C, Szkudlarek M, Hasselquist M, Møller JM, Vestergaard A, Nørregaard J, et al. Ultrasonography, magnetic resonance imaging, radiography, and clinical assessment of inflammatory and destructive changes in fingers and toes of patients with psoriatic arthritis. Arthritis Res Ther. 2007;9(6):R119.

[30]. Zayat AS, Ellegaard K, Conaghan PG, Terslev L, Hensor EMA, Freeston JE, et al. The specificity of ultrasound-detected bone erosions for rheumatoid arthritis. Ann Rheum Dis. 2015 May;74(5):897-903.

[31]. Bajaj S, Lopez-Ben R, Oster R, Alarcón GS. Ultrasound detects rapid progression of erosive disease in early rheumatoid arthritis: a prospective longitudinal study. Skeletal Radiol. 2007 Feb;36(2):123-8.

[32]. Scheel A, Schmidt W, Hermann K, Bruyn G, D’Agostino M, Grassi W, et al. Interobserver reliability of rheumatologists performing musculoskeletal ultrasonography: results from a EULAR "Train the trainers" course. Ann Rheum Dis. 2005 Jul;64(7):1043-9. [33]. Zhang W, Doherty M, Leeb BF, Alekseeva L, Arden NK, Bijlsma JW, et al. EULAR evidence-based recommendations for the diagnosis of hand osteoarthritis: report of a task force of ESCISIT. Ann Rheum Dis. 2009 Jan;68(1):8-17.

[34]. Szkudlarek M, Terslev L, Wakefield RJ, Backhaus M, Balint PV, Bruyn GAW, et al. Summary Findings of a Systematic Literature Review of the Ultrasound Assessment of Bone Erosions in Rheumatoid Arthritis. J Rheumatol. 2016 Jan;43(1):12-21.

[35]. Tămaş M-M, Filippucci E, Becciolini A, Gutierrez M, Di Geso L, Bonfiglioli K, et al. Bone erosions in rheumatoid arthritis: ultrasound findings in the early stage of the disease.

Rheumatol Oxf Engl. 2014 Jun;53(6):1100-7.

[36]. Ohrndorf S, Messerschmidt J, Reiche BE, Burmester GR, Backhaus M. Evaluation of a new erosion score by musculoskeletal ultrasound in patients with rheumatoid arthritis: is US ready for a new erosion score? Clin Rheumatol. 2014 Sep;33(9):1255-62.

[37]. Leng X, Xiao W, Xu Z, Zhu X, Liu Y, Zhao D, et al. Ultrasound7 versus ultrasound12 in monitoring the response to infliximab in patients with rheumatoid arthritis. Clin Rheumatol. 2016 Mar;35(3):587-94.

[38]. Dias EM, Lukas C, Landewé R, Fatenejad S, van der Heijde D. Reliability and sensitivity to change of the Simple Erosion Narrowing Score compared with the Sharp-van der Heijde method for scoring radiographs in rheumatoid arthritis. Ann Rheum Dis. 2008 Mar;67(3):375-9.

[39]. Hulsmans HM, Jacobs JW, van der Heijde DM, van Albada-Kuipers GA, Schenk Y, Bijlsma JW. The course of radiologic damage during the first six years of rheumatoid arthritis. Arthritis Rheum. 2000 Sep;43(9):1927-40.

[40]. de Rooy DPC, van der Linden MPM, Knevel R, Huizinga TWJ, van der Helm-van Mil AHM. Predicting arthritis outcomes--what can be learned from the Leiden Early Arthritis Clinic? Rheumatol Oxf Engl. 2011 Jan;50(1):93-100.

[41]. Szkudlarek M, Narvestad E, Klarlund M, Court-Payen M, Thomsen HS, Østergaard M. Ultrasonography of the metatarsophalangeal joints in rheumatoid arthritis: comparison with magnetic resonance imaging, conventional radiography, and clinical examination. Arthritis Rheum. 2004 Jul;50(7):2103-12. 
[42]. Døhn UM, Ejbjerg BJ, Court-Payen M, Hasselquist M, Narvestad E, Szkudlarek M, et al. Are bone erosions detected by magnetic resonance imaging and ultrasonography true erosions? A comparison with computed tomography in rheumatoid arthritis metacarpophalangeal joints. Arthritis Res Ther. 2006;8(4):R110.

[43]. Mandl P, Supp G, Baksa G, Radner H, Studenic P, Gyebnar J, et al. Relationship between radiographic joint space narrowing, sonographic cartilage thickness and anatomy in rheumatoid arthritis and control joints. Ann Rheum Dis. 2015 Nov;74(11):2022-7. 


\section{Optimization of ultrasonographic examination for}

\section{the diagnosis of erosive Rheumatoid Arthritis in}

comparison to erosive hand Osteoarthritis

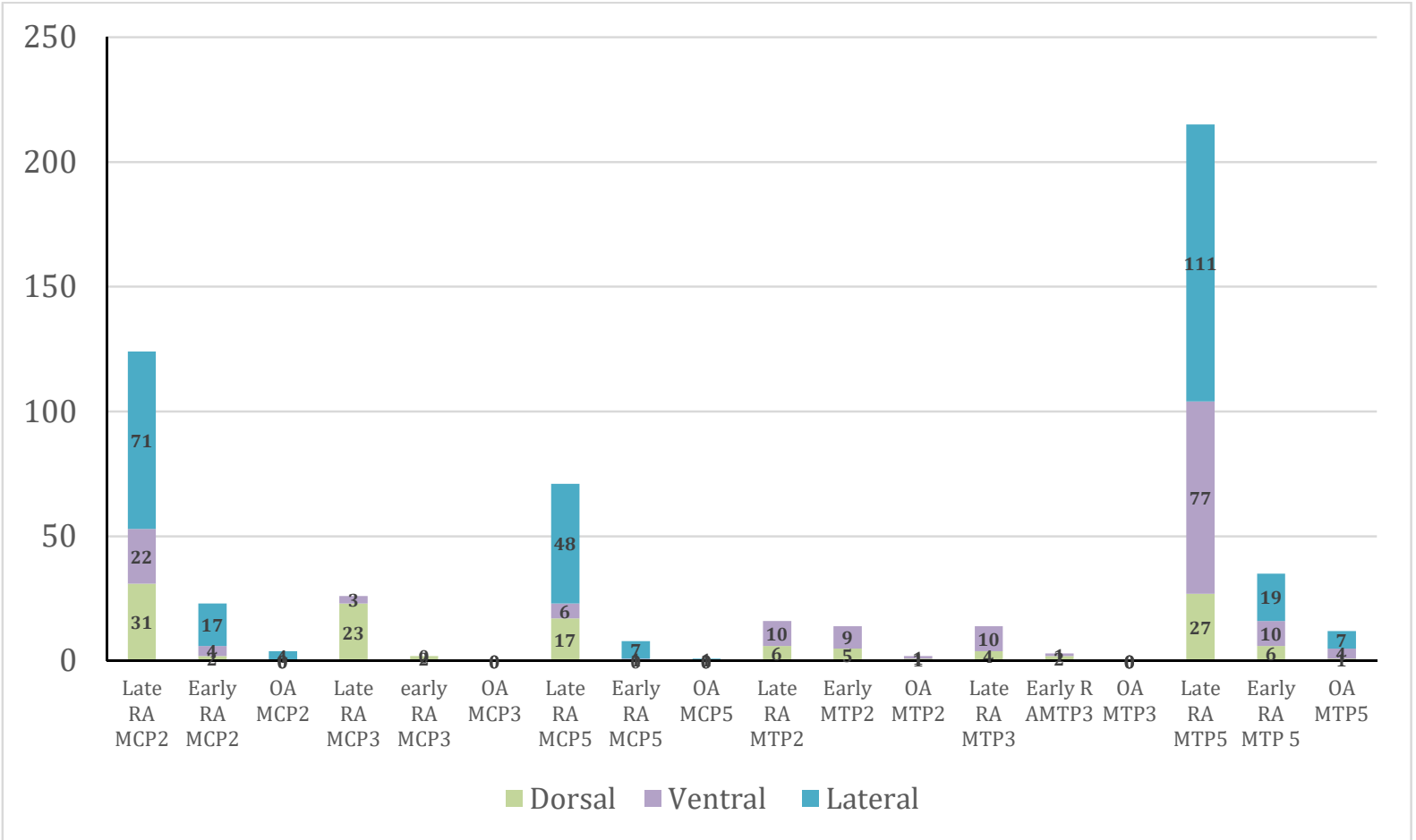

Figure 1: Spatial localization of US erosion for each joint and for late rheumatoid arthritis (RA) $(n=90)$, early $R A(n=32)$ and osteoarthritis (OA) $(n=46)$ diseases. Dorsal (green), ventral (purple) and lateral (blue) joint facets of metacarpophalangeal (MCP) joints and metatarsophalangeal (MTP) joints. 


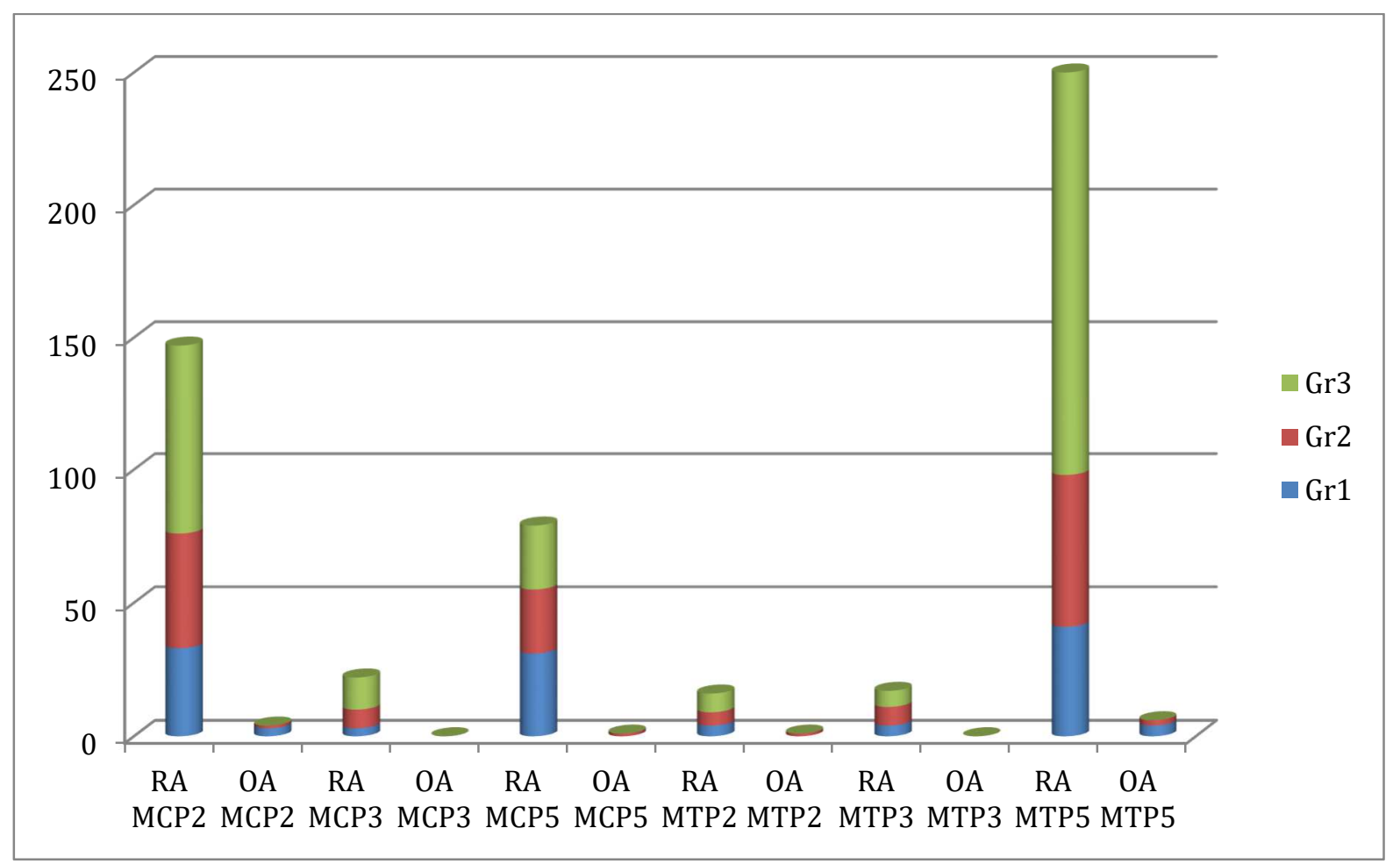

Figure 2: Severity of US erosion for each targeted joints: grade 1 (blue) $=$ single erosion $<2 \mathrm{~mm}$ in its largest dimension, grade $2(\mathrm{red})=$ single erosion $\geq 2 \mathrm{~mm}$ and $<3$ $\mathrm{mm}$ in its largest dimension or no more than two erosions $<2 \mathrm{~mm}$; and grade 3 (green) $=$ single erosion $\geq$ to $3 \mathrm{~mm}$ in its largest dimension or multiple erosions $(>n=2)$ for rheumatoid arthritis (RA) $(n=122)$ and osteoarthritis (OA) $(n=46)$. MCP: metacarpophalangeal joints, MTP: metatarsophalangeal joints. 


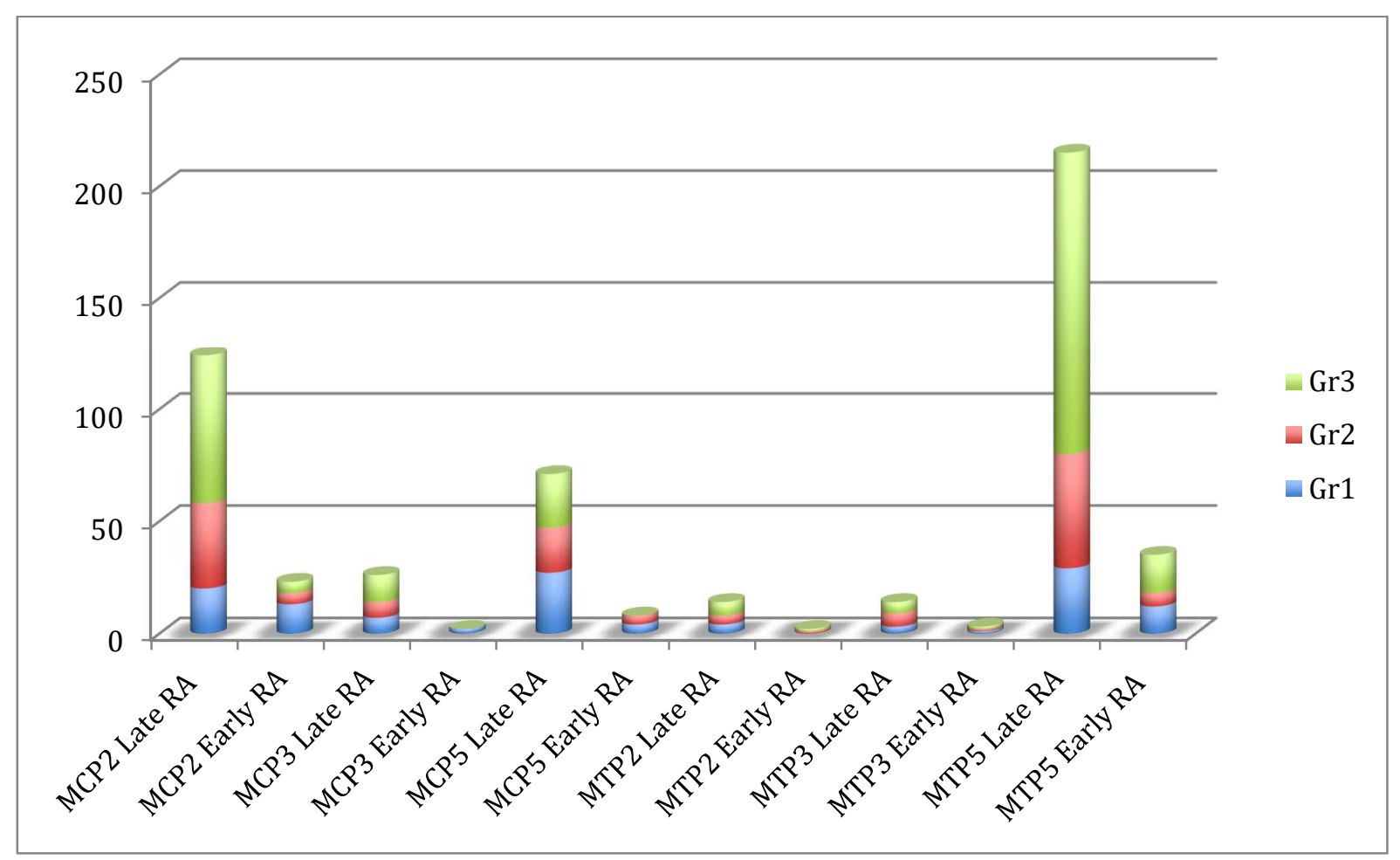

Figure 3: Severity of US erosion for each targeted joints for late $(n=90)$ and early $(\mathbf{n = 3 2}) \mathbf{R A}$ : grade 1 (blue) = single erosion $<2 \mathrm{~mm}$ in its largest dimension, grade $2(\mathrm{red})=$ single erosion $\geq 2 \mathrm{~mm}$ and $<3 \mathrm{~mm}$ in its largest dimension or no more than two erosions $<2 \mathrm{~mm}$; and grade 3 (green) $=$ single erosion $\geq$ to $3 \mathrm{~mm}$ in its largest dimension or multiple erosions $(>n=2)$. MCP: metacarpophalangeal joints, MTP: metatarsophalangeal joints. 


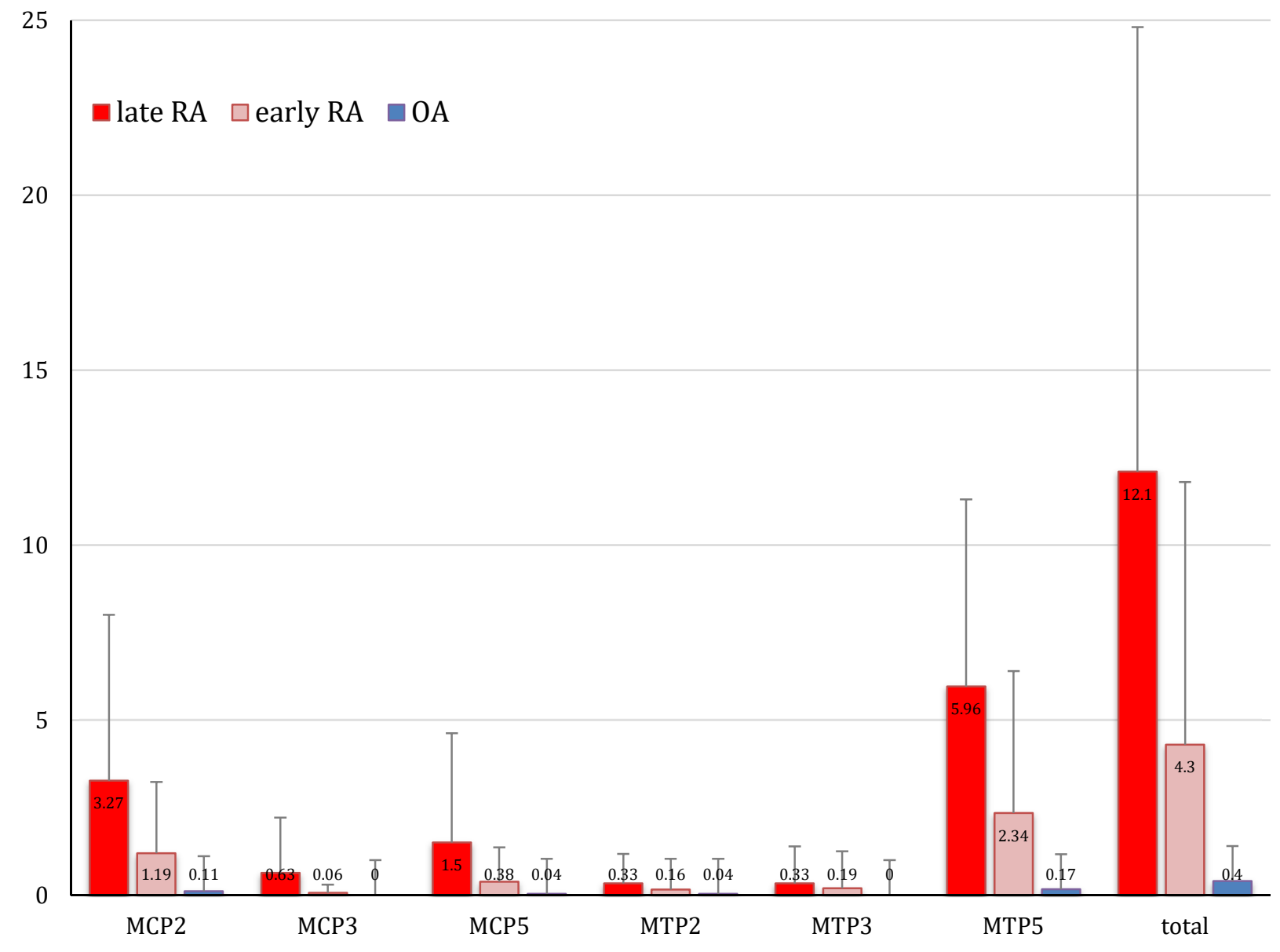

Figure 4: USSe (ultrasound score for erosion) for each joint and for late rheumatoid arthritis (RA) (red) $(n=90)$, early rheumatoid arthritis (RA) (pink) $(n=32)$, and osteoarthritis (OA) (blue) $(n=46)$. MCP: metacarpophalangeal joints, MTP: metatarsophalangeal joints 

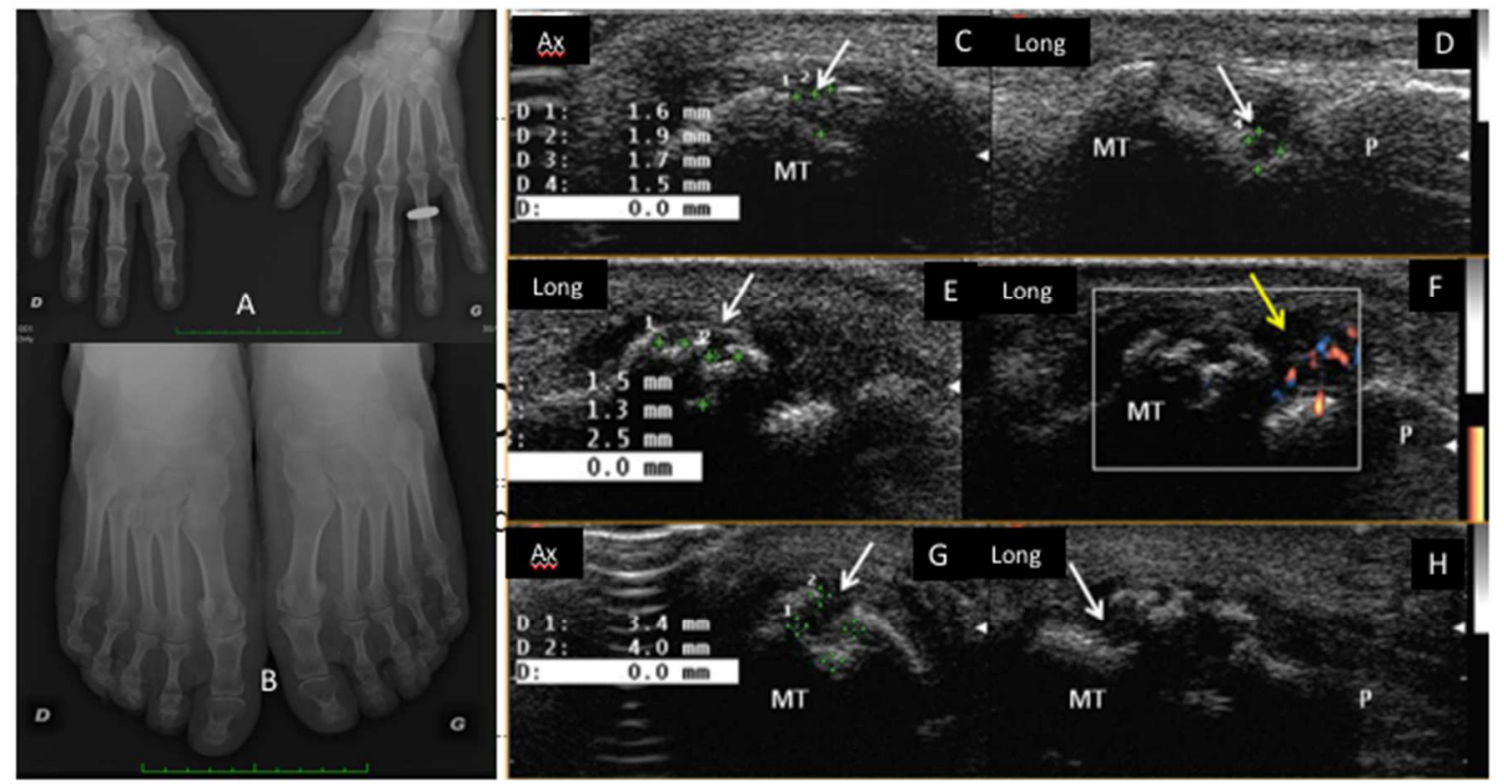

Figure 5 : Early RA patient without erosion on AP hands (A) and feet (B) radiography. On ultrasound examination 3 erosions were detected on axial and longitudinal scans : erosion (white arrow) of grade 1 of the plantar facet of the right MTP5 on B-mode scan (C,D), erosion of grade 2 of the plantar facet of the right MTP5 joint on B mode (white arrow) and DP-mode with active synovitis (yellow arrow) $(E, F)$ and finally erosion of grade 3 of the lateral facet of the left MTP5 joint $(G, H)$. 
Optimization of ultrasonographic examination for the diagnosis of erosive Rheumatoid Arthritis in comparison to erosive hand Osteoarthritis 
Table 1 Characteristics of patients

\begin{tabular}{|c|c|c|c|c|c|c|c|c|}
\hline & \multicolumn{2}{|c|}{$\begin{array}{l}\text { Rheumatoid Arthritis } \\
\qquad \begin{array}{c}\mathbf{N}=\mathbf{1 2 2} \\
(72.6 \%)\end{array} \\
\end{array}$} & \multicolumn{2}{|c|}{ 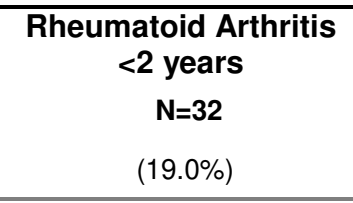 } & \multicolumn{2}{|c|}{$\begin{array}{c}\text { Rheumatoid Arthritis } \\
\geq 2 \text { years } \\
\mathbf{N}=90 \\
(53.6 \%) \\
\end{array}$} & \multicolumn{2}{|c|}{$\begin{array}{l}\text { Osteoarthritis } \\
\qquad \begin{array}{c}\mathbf{N}=46 \\
(27.4 \%) \\
\end{array}\end{array}$} \\
\hline & $\mathrm{N}(\%)$ & Mean(SD) & $N(\%)$ & Mean(SD) & $N(\%)$ & Mean(SD) & $N(\%)$ & Mean(SD) \\
\hline Age & 122 & $54.9(13.5)$ & 32 & $54.3(15.7)$ & 90 & $55.1(12.7)$ & 46 & $56.8(9.6)$ \\
\hline \multicolumn{9}{|l|}{ Gender } \\
\hline Male & $34(27.9)$ & & $10(31.3)$ & & $24(26.7)$ & & $10(21.7)$ & 21.7 \\
\hline Female & $88(72.1)$ & & $22(68.8)$ & & $66(73.3)$ & & $36(78.3)$ & 78.3 \\
\hline Disease duration (years) & 122 & $7.1(7.2)$ & 32 & $0.9(0.4)$ & 90 & $9.3(7.1)$ & 46 & $6.2(8.1)$ \\
\hline Delay between RX and US (days) & 122 & $0.6(6.9)$ & 32 & $0.8(7.5)$ & 90 & $0.5(6.7)$ & 46 & $39.7(269.2)$ \\
\hline NSAIDs & $16(13.1)$ & & $1(3.1)$ & & $15(16.7)$ & & 0 & 0.0 \\
\hline Corticosteroids & $68(55.7)$ & & $18(56.3)$ & & $50(55.6)$ & & 0 & 0.0 \\
\hline SDMARDS & $94(77)$ & & $23(71.9)$ & & $71(78.9)$ & & 0 & 0.0 \\
\hline bDMARD & $37(30.3)$ & & $2(6.3)$ & & $35(38.9)$ & & 0 & 0.0 \\
\hline ESR & 121 & $22.5(20.2)$ & 32 & $32.2(26.5)$ & 89 & 19.1(16.3) & 0 & \\
\hline CRP (mg/l) & 122 & $10.8(22.6)$ & 32 & $19.5(31.6)$ & 90 & $7.7(17.6)$ & 0 & \\
\hline ACPA & $84(68.9)$ & & $21(65.6)$ & & $63(70.0)$ & & 0 & 0.0 \\
\hline ACPA (titers) & 106 & $357.7(696.1)$ & 27 & $526.1(893.5)$ & 79 & $300.1(610.8)$ & 0 & \\
\hline $\mathbf{R F}$ & $70(57.4)$ & & $17(53.1)$ & & $53(58.9)$ & & 0 & 0.0 \\
\hline RF (titers) & 98 & $88.4(161.8)$ & 27 & $69.5(139.2)$ & 71 & $95.5(170.0)$ & 0 & \\
\hline DAS 28 & 117 & $3.6(1.4)$ & 29 & $4.3(1.8)$ & 88 & $3.4(1.2)$ & 0 & \\
\hline
\end{tabular}

N: number; SD: Standard deviation; NSAIDS: non-steroidal anti-inflammatory drugs, sDMARDs: synthetic DMARDS, bDMARDs: biologic DMARDS, ESR: erythrocyte sedimentation rate, CRP: C- 
Table 2: Distribution and prevalence of eroded joints in rheumatoid arthritis, early rheumatoid arthritis and osteoarthritis for joints evaluated on modified Sharp/van der Heijde score.

\begin{tabular}{|c|c|c|c|c|c|c|}
\hline & $\begin{array}{c}\text { Rheumatoid } \\
\text { Arthritis } \\
(n=122)\end{array}$ & $\begin{array}{l}\text { Osteoarthritis } \\
\qquad(n=46)\end{array}$ & & $\begin{array}{l}\text { Early Rheumatoid } \\
\text { Arthritis } \\
(n=32)\end{array}$ & $\begin{array}{l}\text { Osteoarthritis } \\
\qquad(\mathrm{n}=46)\end{array}$ & \\
\hline & $\mathrm{Nb}$ of eroded joint & $\mathrm{Nb}$ of eroded joint & $p$ & $\mathrm{Nb}$ of eroded joint & $\mathrm{Nb}$ of eroded joint & $\mathrm{p}$ \\
\hline WRIST & 50 & 10 & 0.0722 & 5 & 10 & 0.7345 \\
\hline MCP1。 & 17 & 0 & 0.0164 & 2 & 0 & 0.0952 \\
\hline MCP2 & 23 & 1 & 0.0168 & 1 & 1 & 0.0098 \\
\hline MCP3 & 12 & 0 & 0.0363 & 1 & 0 & 0.4103 \\
\hline MCP4 & 4 & 0 & 0.5758 & 1 & 0 & 0.4103 \\
\hline MCP5 & 5 & 0 & 0.5758 & 1 & 0 & 0.4103 \\
\hline IPP1\% & 0 & 0 & - & 0 & 0 & - \\
\hline IPP2 & 2 & 4 & 0.1269 & 2 & 4 & 0.9616 \\
\hline IPP3 & 6 & 5 & 0.3935 & 1 & 5 & 0.6401 \\
\hline IPP4 & 2 & 5 & 0.1269 & 0 & 5 & 0.2647 \\
\hline IPP5 & 1 & 0 & 1.0000 & 0 & 0 & - \\
\hline IP1 & 10 & 1 & 0.2884 & 3 & 1 & 0.5646 \\
\hline MTP1000 & 16 & 2 & 0.1592 & 1 & 2 & 0.7824 \\
\hline MTP2 & 20 & 1 & 0.0710 & 0 & 1 & 0.0327 \\
\hline MTP3 & 24 & 0 & 0.0045 & 3 & 0 & 0.0452 \\
\hline MTP4 & 17 & 0 & 0.0127 & 2 & 0 & 0.1652 \\
\hline MTP5 & 63 & 0 & $<0.0001$ & 8 & 0 & 0.0035 \\
\hline Mean of eroded joint $\pm S^{*}$ & $2.23 \pm 3.1$ & $0.63 \pm 1.24$ & $<0.0001$ & $0.97 \pm 1.58$ & $0.63 \pm 1.24$ & $<0.0001$ \\
\hline Mean of $\mathrm{SHSe}^{\star \star} \pm \mathrm{SD}$ & $5.98 \pm 11.09$ & $1.09 \pm 2.58$ & $<0.0001$ & $1.62 \pm 3.09$ & $1.09 \pm 2.58$ & $<0.0001$ \\
\hline
\end{tabular}

$\mathrm{N}$ : number ; SD : Standard Deviation, Mean SHSe: Mean Modified Sharp/van der Heijde score for erosion; MCP: metacarpophalangeal joints, IPP/IP: proximal Interphalangeal joints; MTP: metarsophalangeal joint; $p$ : Chi-2 Test 
Table 3: Difference of prevalence for eroded joints between OA and RA and OA and early RA for joints evaluated on USSe

\begin{tabular}{|c|c|c|c|c|c|c|c|}
\hline & & $\begin{array}{l}\mathbf{R A}(\mathbf{n}=\mathbf{1 2 2}) \\
\mathrm{nb} \text { of eroded joint }\end{array}$ & $\begin{array}{c}\text { OA }(n=46) \\
n b \text { of eroded joint }\end{array}$ & $\mathbf{p}$ & $\begin{array}{l}\text { Early } \mathbf{R A}(\mathrm{n}=32) \\
\mathrm{nb} \text { of eroded joint }\end{array}$ & $\begin{array}{c}\text { OA }(n=46) \\
n b \text { of eroded joint }\end{array}$ & $p$ \\
\hline \multirow[t]{4}{*}{ MCP2 $^{\circ}$} & $D$ & 33 & 0 & 0.0012 & 2 & 0 & 0.0564 \\
\hline & $P$ & 26 & 0 & 0.0037 & 4 & 0 & 0.0252 \\
\hline & $\mathrm{L}$ & 88 & 4 & $<0.0001$ & 17 & 4 & 0.0019 \\
\hline & tot $^{+}$ & 147 & 4 & $<0.0001$ & 23 & 4 & 0.0008 \\
\hline \multirow[t]{3}{*}{ MCP3 } & $D$ & 25 & 0 & 0.0034 & 2 & 0 & 0.0564 \\
\hline & $P$ & 3 & 0 & 0.5626 & 0 & 0 & - \\
\hline & tot & 28 & 0 & 0.0034 & 2 & 0 & 0.0564 \\
\hline \multirow[t]{4}{*}{ MCP5 } & $D$ & 17 & 0 & 0.0453 & 0 & 0 & - \\
\hline & $P$ & 7 & 0 & 0.1901 & 1 & 0 & 0.4103 \\
\hline & $\mathrm{L}$ & 55 & 1 & $<0.0001$ & 7 & 1 & 0.0283 \\
\hline & tot & 79 & 1 & $<0.0001$ & 8 & 1 & 0.0396 \\
\hline \multirow[t]{3}{*}{ MTP2 $^{\circ \circ}$} & $\mathrm{D}$ & 6 & 1 & 0.6751 & 1 & 1 & 0.7938 \\
\hline & $P$ & 10 & 0 & 0.0634 & 1 & 0 & 0.4103 \\
\hline & tot & 16 & 1 & 0.0727 & 2 & 1 & 1.0000 \\
\hline \multirow[t]{3}{*}{ MTP3 } & $\mathrm{D}$ & 6 & 0 & 0.3234 & 2 & 0 & 0.4103 \\
\hline & $P$ & 11 & 0 & 0.0634 & 1 & 0 & 0.4103 \\
\hline & tot & 17 & 0 & 0.0379 & 3 & 0 & 0.4103 \\
\hline \multirow[t]{4}{*}{ MTP5 } & $D$ & 33 & 1 & 0.0026 & 6 & 1 & 0.0396 \\
\hline & $P$ & 87 & 1 & $<0.0001$ & 10 & 1 & 0.0071 \\
\hline & $\mathrm{L}$ & 130 & 4 & $<0.0001$ & 19 & 4 & 0.0003 \\
\hline & tot & 250 & 6 & $<0.0001$ & 35 & 6 & 0.0009 \\
\hline $\begin{array}{l}\text { Mean of eroded } \\
\text { joint } \pm \mathrm{SD}^{*}\end{array}$ & & $4.4 \pm 4.7$ & $0.3 \pm 0.4$ & $<0.0001$ & $2.3 \pm 3.4$ & $0.3 \pm 0.4$ & $<0.0001$ \\
\hline Mean USSe $^{\star \star} \pm S D$ & & $10.0 \pm 12.0$ & $0.4 \pm 0.7$ & $<0.0001$ & $4.3 \pm 7.5$ & $0.4 \pm 0.7$ & $<0.0001$ \\
\hline
\end{tabular}

Standard Deviation, ${ }^{* *}$ Mean of total Erosive Score US, ${ }^{\diamond}$ Number of eroded joint, ${ }^{\circ} \mathrm{MCP}$ Metacarpophalangeal joints, ${ }^{\circ}$ MTP Metarsophalangeal joints, ${ }^{\dagger}$ Total,

D: Dorsal, P: Plantar/Palmar, L: Lateral, p: Chi-2 Test 
Table 4: Sensitivity (Se) and Specificity (Sp) of different scenarios (joints or joint facets selected) of eroded RA on US according to erosion of at least a grade 2 or at least two eroded joint facets.

Erosion on US $\geq$ grade 2 at the joint facet level $R X+(n=42)$

$\geq 2$ eroded joint facets on US

$\mathrm{RX}+(\mathrm{n}=42)$

\begin{tabular}{|c|c|c|c|c|c|c|c|c|c|c|c|c|c|c|c|c|c|}
\hline Scenarios & $\operatorname{Fac}(\mathbf{n})^{\star}$ & $\mathbf{R A}^{\circ}$ & $\begin{array}{c}\text { Early } \\
\text { RA }\end{array}$ & $\mathbf{O A}^{\circ \circ}$ & $\mathrm{Se}$ & Sp & PPV & NPV & $\mathbf{A g} \% \diamond$ & RA & $\begin{array}{c}\text { Early } \\
\text { RA }\end{array}$ & OA & $\mathrm{Se}$ & Sp & PPV & NPV & $\mathrm{Ag} \%$ \\
\hline All joints of the USSe & 30 & & & & & & & & & & & & & & & & \\
\hline Number of patients eroded & & 81 & 11 & 5 & 66.4 & 89.1 & 94.2 & 50.0 & 92.8 & 83 & 14 & 0 & 68.0 & 100 & 100 & 54.1 & 90.4 \\
\hline MCP2+MCP5+MTP5 & 18 & & & & & & & & & & & & & & & & \\
\hline Number of patients eroded & & 79 & 11 & 4 & 64.7 & 91.3 & 95.2 & 49.4 & 92.8 & 81 & 14 & 0 & 66.4 & 100 & 100 & 52.9 & 90.4 \\
\hline MCP2+MTP5 & 12 & & & & & & & & & & & & & & & & \\
\hline Number of patients eroded & & 78 & 11 & 3 & 63.9 & 93.5 & 96.3 & 49.4 & 92.8 & 77 & 14 & 0 & 63.1 & 100 & 100 & 50.5 & 88.1 \\
\hline MCP2L+MCP5L+MTP5 $(P+L)^{\dagger}$ & 8 & & & & & & & & & & & & & & & & \\
\hline Number of patients eroded & & 74 & 10 & 3 & 60.7 & 93.5 & 96.1 & 47.2 & 92.8 & 75 & 12 & 0 & 61.5 & 100 & 100 & 49.5 & 88.1 \\
\hline MCP2L+MTP5 (P+L) & 6 & & & & & & & & & & & & & & & & \\
\hline Number of patients eroded & & 74 & 10 & 2 & 60.7 & 95.6 & 97.4 & 47.8 & 92.8 & 73 & 12 & 0 & 59.8 & 100 & 100 & 48.4 & 88.1 \\
\hline
\end{tabular}

Number of patients eroded

$\begin{array}{lllllll}74 & 10 & 2 & 60.7 & 95.6 & 97.4 & 47.8\end{array}$

${ }^{\dagger}$. MCP : metacarpophalangeal joints, MTP metarsophalangeal joints, P: Plantar, L : Lateral

RX+: EULAR 2013 Definition; US: Ultrasounds; Se : sensitivity \%, Sp: specificity \%, PPV: positive predictive value \%; NPV: negative predictive value \% 